\title{
Mobile Application and a Web-Based Geographic Information System for Sharing Geological Hazards Information in East and Southeast Asia
}

\author{
Joel Bandibas, Shinji Takarada \\ Geological Survey of Japan, AIST, Tsukuba, Japan \\ Email: joel.bandibas@aist.go.jp
}

How to cite this paper: Bandibas, J. and Takarada, S. (2019) Mobile Application and a Web-Based Geographic Information System for Sharing Geological Hazards Information in East and Southeast Asia. Journal of Geographic Information System, 11, 309-320.

https://doi.org/10.4236/jgis.2019.113018

Received: April 16, 2019

Accepted: May 17, 2019

Published: May 20, 2019

Copyright $\odot 2019$ by author(s) and Scientific Research Publishing Inc. This work is licensed under the Creative Commons Attribution International License (CC BY 4.0).

http://creativecommons.org/licenses/by/4.0/

\section{c) (i) Open Access}

\begin{abstract}
This paper presents a mobile application and a web-based geographic information system for an efficient and cost-effective sharing of geological hazards information in East and Southeast Asia. The information system uses the Open Geospatial Consortium (OGC), Web Map Service (WMS) and Web Processing Service (WPS) for spatial data rendition and processing online. Free and Open Source Software (FOSS) is also used for other important spatial data processing and sharing operations. WMS and WPS are formulated to access and view the geological hazard data in the system's database. The mobile application is developed to access and share the system's geospatial contents by sending requests to these web services. The application also makes geological hazard mitigation measures more effective by incorporating the mobile device's GPS location information with geological hazard data. Information like the distance from the nearest active fault, active volcano and earthquake hypocenter can be easily determined using the application. The mobile application provides an interface for the users to easily access geological hazard information such as active fault, active volcanoes, shorelines inundated by tsunamis, and historical and real time seismic events. The widespread use of mobile devices with Internet connection makes geological hazard information dissemination very efficient using the application. The mobile application is called G-EVER Mobile. G-EVER stands for Asia Pacific Region Global Earthquake and Volcanic Eruption Risk Management consortium. The application can be accessed at

https://ccop-geoinfo.org/gever-mo/index.php.
\end{abstract}

\section{Keywords}

Mobile Application, WebGIS, OGC, WMS, WPS, FOSS, Geological Hazards 
Information

\section{Introduction}

An efficient and highly accessible geological hazard information system is indispensable for an effective geological hazard mitigation endeavor. This kind of information system requires the use of Geographic Information System (GIS) software to make it more efficient and cost-effective for spatial information processing, management and storage [1] [2]. Currently, the conventional spatial information system is inefficient in meeting the geospatial information and spatial data processing needs of many users because the GIS software and data are installed and stored in a standalone computer, respectively. A new type of spatial information system wherein the GIS software and geospatial data are installed and stored in a remote server is starting to be the preferred system for many kinds of endeavors needing geospatial data. The system has assigned Uniform Resource Locator (URL) that users with internet access can use to access the system for their spatial data processing needs. The information system is called Web-based Geographic Information System (WebGIS). WebGIS has been widely used in many endeavors needing geospatial data [e.g. [3] [4] [5] [6] [7]]. The work of Bandibas and Takada [8] shows that it can be used to share diverse and huge volume of geospatial data. On the other hand, several research undertakings use WebGIS for processing and sharing hazard information to the general public. Miao and Yuan [9] designed the Information System for Geological Disaster Monitoring and Warning (ISGDM), a WebGIS used for geological disaster mitigation. Tobita et al. [10] developed an information system dedicated to promote earthquake disaster mitigation practices in Japan using WebGIS. On the other hand, Cozannet et al. [11] created a WebGIS system for disaster risk reduction in areas near volcanoes. Aye et al. [12] showed that WebGIS can be customized as an interactive tool for risk analysis of natural hazards like floods and landslides. Furthermore, WebGIS can also be utilized as a landslide early warning system as shown by the work of Hou et al. [13]. A WebGIS system has three main components: the Database, Web Services and Applications. The Web Services component provides a wide array of spatial data rendition, processing and retrieval functions, and serves as the go-between for the Application and the geospatial contents in the Database component. The spatial information system's set up follows the Spatial Data Infrastructure (SDI) model as proposed by Stefanakis and Prastacos [14]. Furthermore, the Open Geospatial Consortium (OGC) Web Map Service (WMS) and Web Processing Service (WPS) are widely used web services in WebGIS system. The use of mobile application in sharing geological hazard information to many users is very efficient because of the widespread use of mobile devices in recent years. The application formulates and sends the web services requests to the Web Services component of a WebGIS to access, render and share the geological hazard information in the system data- 
base. The location information provided by the mobile device can also make geohazard information more useful to many users.

Geological related natural disasters frequently happen in many countries in East and Southeast Asia. The Asia Pacific Region Global Earthquake and Volcanic Eruption Risk Management consortium's (G-EVER) main objective is to mitigate the effects of geological hazard in the region. Timely dissemination of geological hazard information is crucial to abate the effects of geological hazards. This paper presents a mobile application and a WebGIS system developed to efficiently share geological hazard information to the general public. The different components of the information system and the web services that are formulated to access, render and share geological hazard information will be explained. Details of the mobile application, how it is used to formulate the web services requests and share geological hazard information will also be presented. Furthermore, the use of the mobile device's location information to determine the distance between the user and geological phenomena will also be illustrated.

\section{G-EVER WebGIS Components}

The information system presented in this paper is called G-EVER WebGIS. The components of the information system consist of the Database, Web Services and Application as shown in Figure 1. The geological hazard information is provided by the members of the G-EVER consortium. The real time seismic event information is obtained from the USGS Earthquake Hazard Program GeoJson service [15]. Web services are formulated for the geological hazard information obtained from the data sources. The same information is also stored in the system's database. The mobile application accesses the system's geological hazard database by sending requests to the web services components, which will do the spatial data query and other spatial data processing functions.

\subsection{Database}

The G-EVER geospatial database is created and maintained using the open source

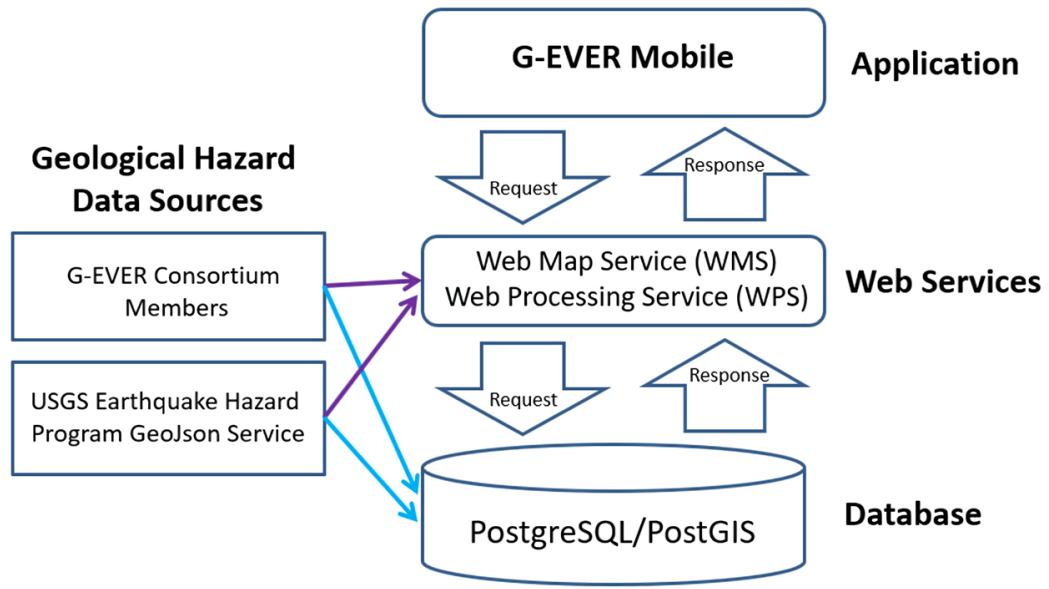

Figure 1. The main components of the G-EVER WebGIS system. 
relational database management software PostgreSQL and its PostGIS extension [16]. The G-EVER geological hazard database contains the following geospatial information:

Active Faults (East and Southeast Asia)

Calderas (East and Southeast Asia)

Earthquakes (1990 to present; World; $M \geq 6$ )

Earthquakes (Past month, week and day; World; $M \geq 4$ )

Earthquakes (Real Time; World; $M \geq 4$ )

Earthquake Source Regions (World)

Geological Map (East and Southeast Asia)

Large-Scale Ignimbrite and Ash Fall Distribution (East and Southeast Asia)

Major Earthquake Occurrence with Fatalities (East and Southeast Asia)

Major Volcanic Eruptions with Fatalities (East and Southeast Asia)

Plate Boundaries (East and Southeast Asia)

Pyroclastic Fall (East and Southeast Asia)

Quaternary Volcanoes (World)

Tsunami Inundated Shorelines (East and Southeast Asia)

Volcanic and Plutonic Rocks (East and Southeast Asia)

The geological hazard data, originally in ArcGIS shapefile format, are converted into PostgreSQL/PostGIS tables using an application. Figure 2 shows the mobile application displaying the active faults map covering East and Southeast Asia.

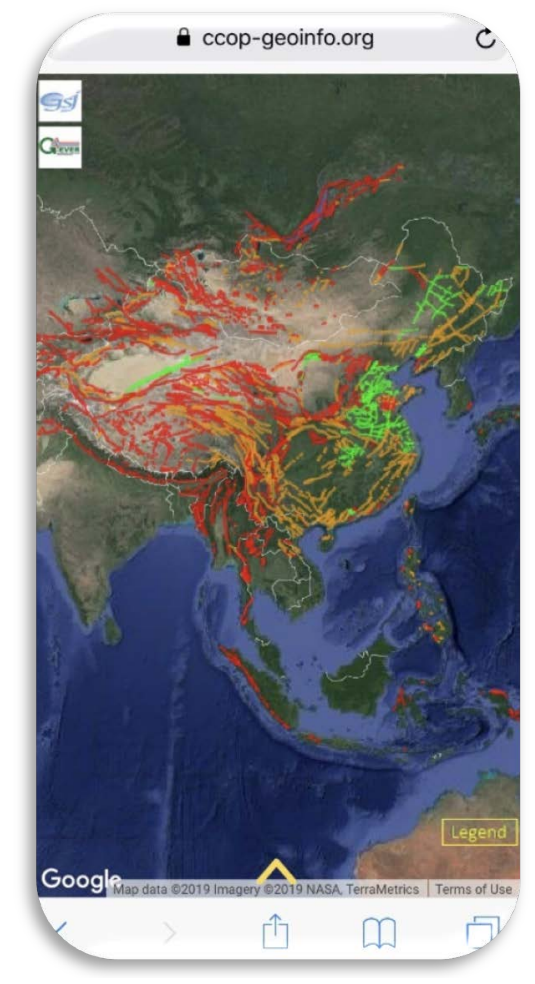

Figure 2. The mobile app showing the active faults map covering East and Southeast Asia. 


\subsection{Web Services}

The Web Services component of the G-EVER WebGIS system uses the OGC WMS and WPS [17] which are used to query the database, display geological hazard information and implement other geospatial data processing functions. The web services are formulated using the open source software Mapserver [18]. WMS provides a simple Hypertext Transfer Protocol (HTTP) interface for requesting geo-registered map images from one or more distributed databases [19]. Figure 3 displays the main components of WMS. WMS services are formulated for all the maps stored in the G-EVER database. WMS request is in the form of a Uniform Resource Identifier (URI). When a request is sent to the WMS server, the WMS software queries the database using the information conveyed through the request URI and generates a response. Figure 4 shows the URI of a GetMap WMS request to query the G-EVER database and retrieve the active fault map covering East Asia.

The WPS provides a standard interface that simplifies the task of making simple or complex geospatial processing using HTTP. It provides a robust, interoperable, and versatile protocol for process execution of web services [20]. The G-EVER WebGIS system formulates several WPS to query the database and data upload and download. WPS requests are in the form of URI which could trigger geoprocessing by executing PHP scripts to execute Structure Query Language (SQL) codes for the requested geospatial processing function. Figure 5 shows the SQL used to retrieve an earthquake information, implemented as a response to a WPS request. The query result is presented as a feature information pop-up by the G-EVER mobile application. The most important WPS provided by G-EVER WebGIS system is the WMS on-the-fly formulation to view real time seismic data. The process includes the automated creation of PostGIS table of the recent earthquakes after the data are obtained from the USGS server.

\subsection{G-EVER Mobile Application}

The G-EVER mobile application is developed to enable the users to access the

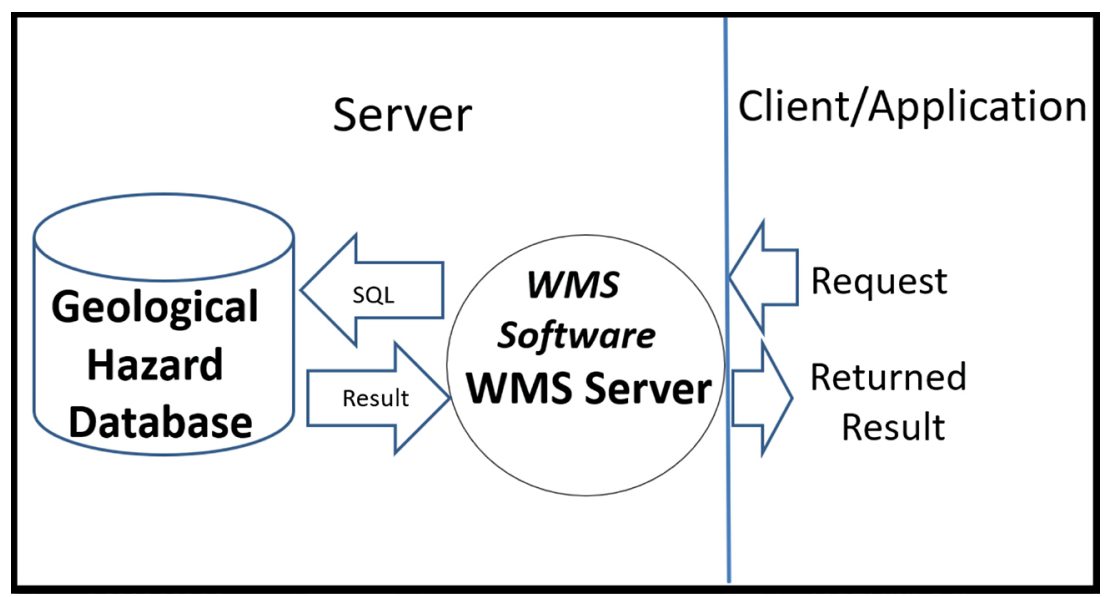

Figure 3. Web Map Service. 


\section{WMS GetMap Request URI}

https://ccop-geoinfo.org/ows/hazardmap_wms/activefaults_mobile_wms?LAYERS=activefaults_mobile \&REQUEST $=$ GetMap\&SERVICE=WMS\&VERSION=1.1.1\&FORMAT=image/png\&SRS=EPSG:4326\&B $\mathrm{BOX}=78.24,-5.99,128.99,46.24 \&$ WIDTH $=512 \&$ HEIGHT $=700$

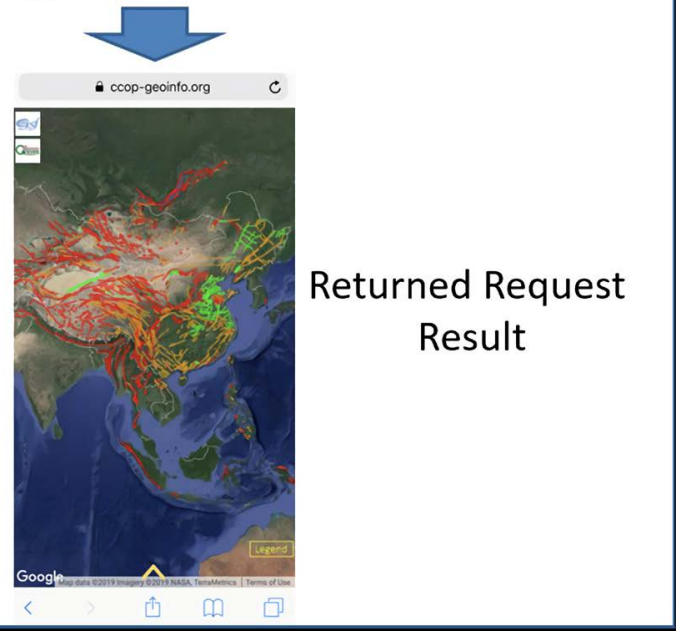

Figure 4. The URI to query the database to retrieve the active fault map of East and Southeast Asia.

\section{SQL to retrieve earthquake information}

\$sql="SELECT longitude,latitude, magnitude,depth,place,time,organization_source,casualties, eventid from 'my_eq_data.earthquake_past_month' order by time desc limit 1";

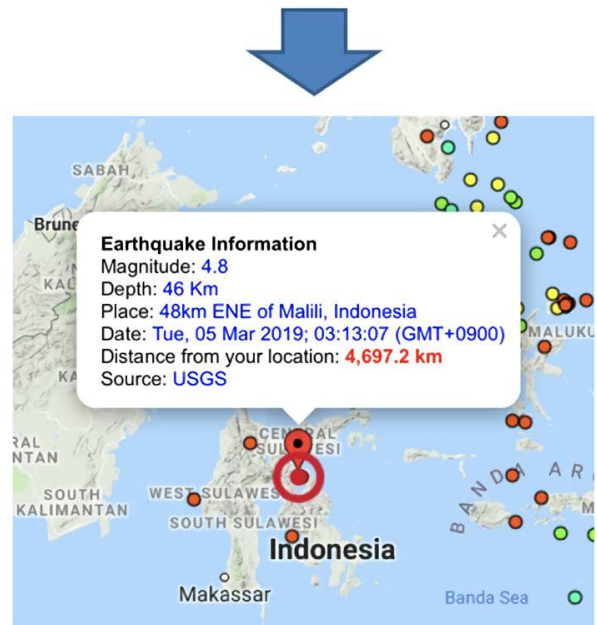

\section{Query result presented as earthquake information popup.}

Figure 5. The SQL to query earthquake information as a response to a WPS request.

geological hazard information easily using their mobile devices. The application is developed using JavaScript and PHP scripts. It also uses the open source Leaflet JavaScript Library [21] for viewing geological hazard maps serve as WMS. It can also display the Google Maps and OpenStreetMap base maps by using the mapping applications' Application Program Interface (API). Figure 6 shows the home screen of the mobile application, which provides an interface for a user to easily view very important information like the recent earthquake occurrences 


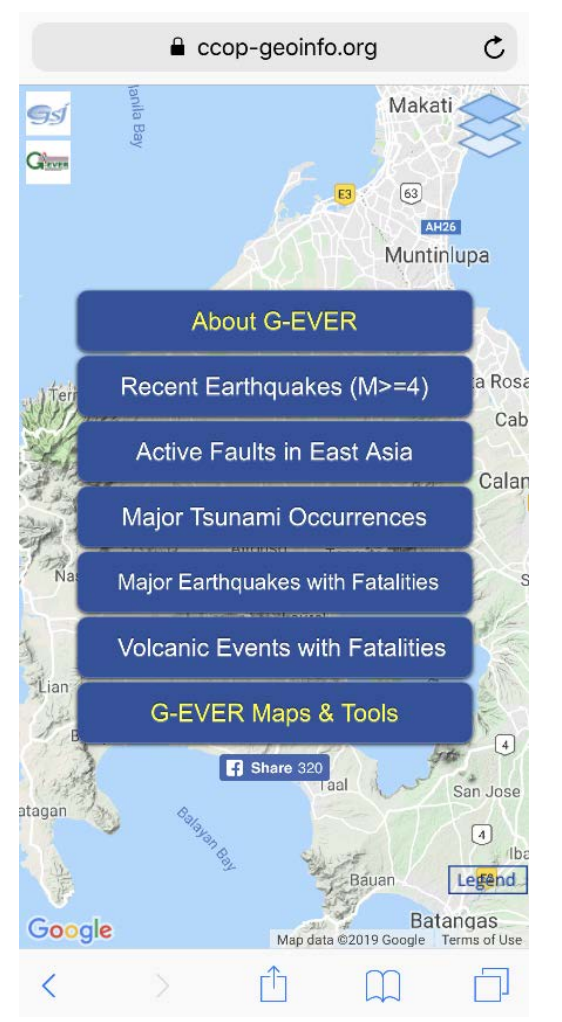

Figure 6. The home screen of the G-EVER Mobile.

worldwide and major volcanic events with fatalities. Figure 7 lists the recent earthquakes worldwide displayed by the mobile device. Moreover, the application provides the list of all geological hazard maps in the G-EVER database. Choosing a map on the list triggers the application to send a WMS GetMap request to the G-EVER system web services component, which then queries the database and returns the map images for viewing. It can also implement a WPS request when a user chooses a feature information on the map. Figure 8 explains the WMS and a WPS request implementation whenever a user chooses an active fault map, then double taps a fault trace in the northern Philippines. The G-EVER web services server processes the requests, then returns the results us active fault map images and information about the chosen active fault. The results are then displayed on the mobile screen as a map and an information pop-up. Figure 9 shows the secondary menu of the mobile application which provides an important interface for searching information in the G-EVER database, map overlay control, Google Maps and OpenStreetMap basemap choices, and location setup.

\section{Hazard Map and GPS Data}

Information about the distance between a location from the nearest geological phenomenon is very important for geological hazard mitigation. The information about the distance of a building to the nearest active fault, for example, is very critical in assessing ground deformation risk for that building. The G-EVER 


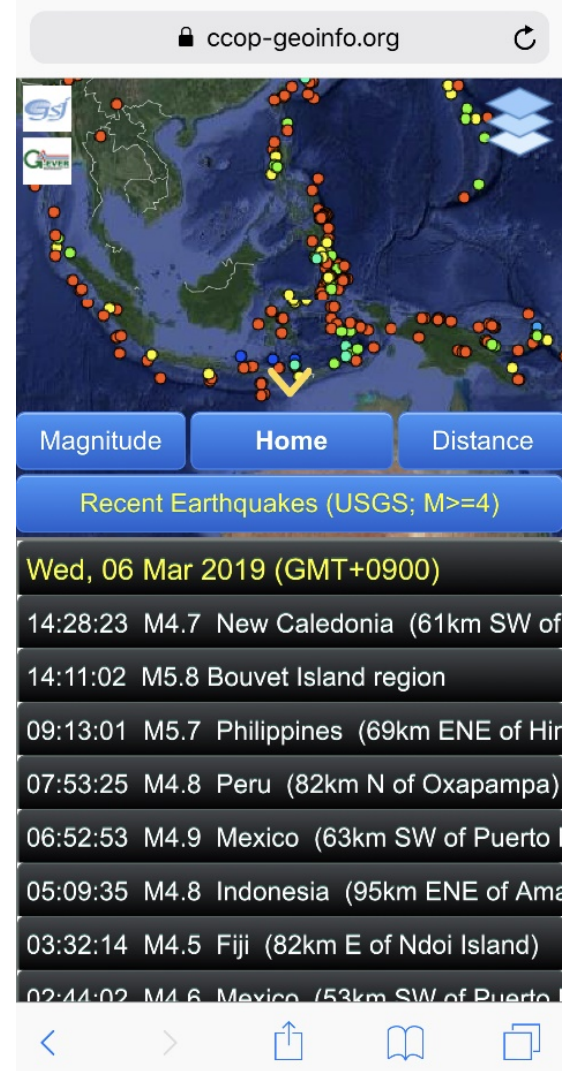

Figure 7. G-EVER Mobile displaying the recent earthquakes worldwide.

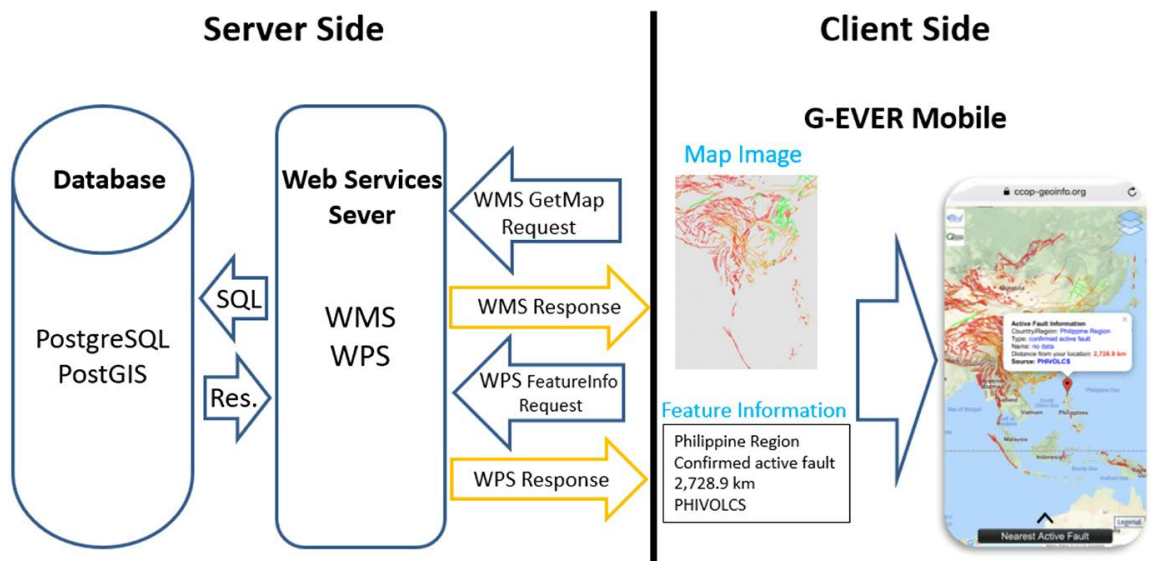

Figure 8. G-EVER Mobile querying the geological hazard database using WMS and WPS requests.

mobile application provides distances information to users using the GPS data and other relevant geospatial data. The application provides information about the distance between the device location and the nearest active fault, seismic event, coastal areas damaged by tsunami, and active volcanoes. Figure 10(a) and Figure 10(b) show the mobile application displaying the distance information between the user and an earthquake epicenter and active fault, respectively. The application can also provide information about the seismic hazard of a place by 


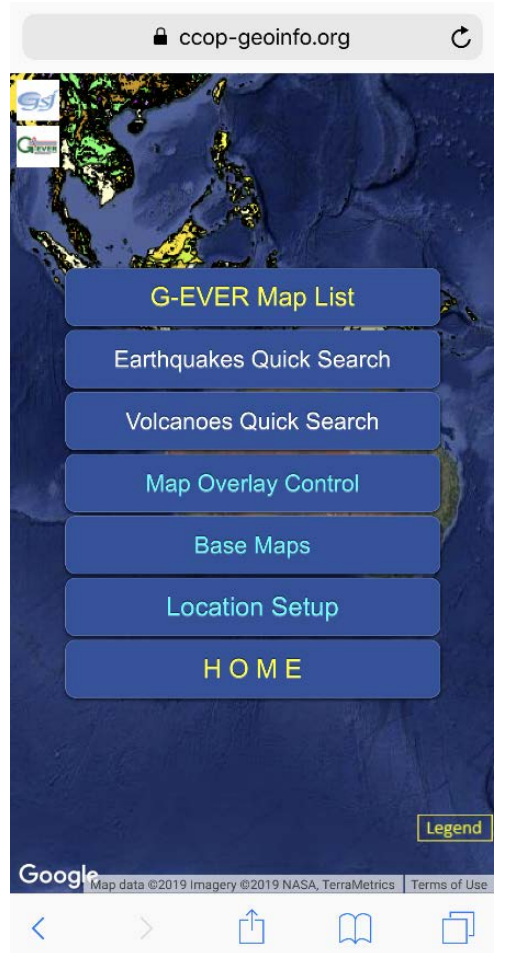

Figure 9. G-EVER Mobile secondary menu buttons.
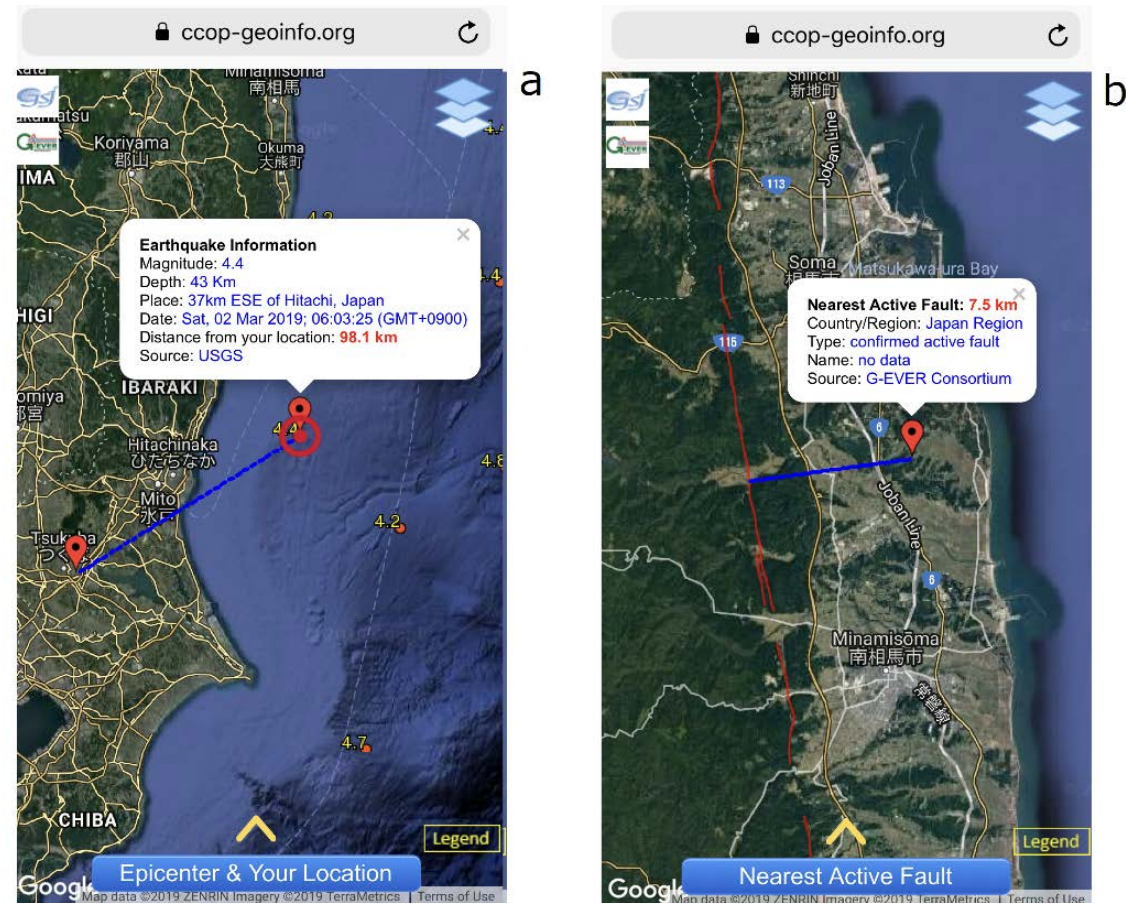

Figure 10. The G-EVER Mobile showing the distance between the user and an earthquake epicenter (a) and an active fault (b).

determining the major earthquakes that occurred near the place, including information about the number and causes of fatalities. Figure 11 lists the major earthquakes and their distances from the user's location. 


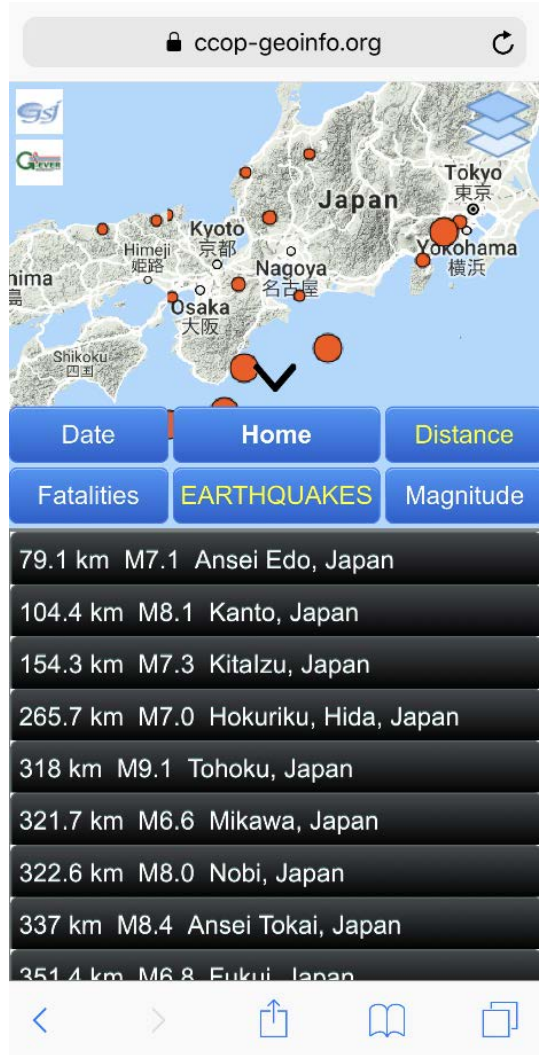

Figure 11. The G-EVER Mobile showing major earthquakes nearest to the user's location.

\section{Discussion}

The Asia-Pacific Region Earthquake and Volcanic Eruption Risk Management (G-EVER) consortium, which consists of the geological surveys and research institutes of the Asia-Pacific countries, was established in 2012. G-EVER aims to implement research projects with the main objective of mitigating the effects of geological hazards caused by earthquakes, tsunamis and volcanic eruptions. The consortium developed the G-EVER WebGIS system to make geological hazard information accessible online. The use of FOSS and OGC web services makes the information system very efficient and cost-effective for sharing geological hazard information with the public. G-EVER Mobile is developed to make the G-EVER geological hazard information accessible to many users because of the widespread use of mobile devices. The application provides easy to use interface to access geological hazard information in the G-EVER database. The G-EVER WebGIS system provides a mobile user with the needed geological hazard information by responding to the web service request generated by the mobile application. The web service request response can be map images or feature information in xml formats, that are rendered on the mobile device screen. Map images are displayed over Google Maps or OpenStreetMap basemap. The mobile application provides a very versatile map viewer which includes map overlay and transparency controls. Users can also double tap any feature information on the 
map to view feature information on a pop-up dialog. The availability of location data in mobile devices makes the mobile application more useful than its desktop computer counterpart. The mobile application provides valuable information like distances between the user's location and the nearest active fault, seismic event and active volcano. The mobile device can also be used as platform for field data capturing and sharing field information. The mobile application is accessible at https://ccop-geoinfo.org/gever-mo/index.php. It will be published in Google Play app store and Apple app store soon.

\section{Conclusion}

The G-EVER Mobile and WebGIS system are successfully developed to share geological hazard information with the general public. The use of OGC web services and FOSS makes the sharing of the hazard information very efficient and cost-effective. The G-EVER mobile application makes geological hazard data more accessible to many users. The mobile application's access to the mobile device's GPS data enables the application to provide additional information that is very important for geological hazard risk mitigation.

\section{Conflicts of Interest}

The authors declare no conflicts of interest regarding the publication of this paper.

\section{References}

[1] Huisman, O., De By, R.A., et al. (2009) Principles of Geographic Information Systems, The International Institute for Geo-Information Science and Earth Observation (ITC), The Netherlands.

[2] Smith, M., Goodchild, M. and Longley, P. (2019) Geospatial Analysis, a Comprehensive Guide to Principles, Techniques and Software Tools. 6th Edition, The Winchelsea Press, Winchelsea, UK. https://www.spatialanalysisonline.com/extractv6.pdf

[3] Lwin, K.K. and Murayama, Y. (2011) Web-Based GIS System for Real-Time Field Data Collection Using Personal Mobile Phone. Journal of Geographic Information System, 3, 382-389. https://doi.org/10.4236/jgis.2011.34037

[4] Sing, P.S., Chutia, D. and Sudhakar, S. (2012) Development of a Web Based GIS Application for Spatial Natural Resources Information System Using Effective Open Source Software and Standards. Journal of Geographic Information System, 4, 261-266. https://doi.org/10.4236/jgis.2012.43031

[5] Anderson, F. and Al-Thani, N.N.J. (2015) Feasibility Study of a National Web-Based GIS Application to Assess the Risk of Pesticide Drift in the U.S. Journal of Geoscience and Environmental Protection, 3, 20-24.

https://doi.org/10.4236/gep.2015.37003

[6] Zerihun, M.E. (2017) Web Based GIS for Tourism Development Using Effective Free and Open Source Software Case Study: Gondor Town and Its Surrounding Area, Ethiopia. Journal of Geographic Information System, 9, 47-58. https://doi.org/10.4236/jgis.2017.91004 
[7] Charoenbunwanon, N., Wakita, K. and Bandibas, J.C. (2016) Web-Based Mineral Information System of Thailand Using Free and Open Source Software and Open Geospatial Consortium standards: A Case Study of ASEAN Region. Geoinformatics, 27, 31-39. https://doi.org/10.6010/geoinformatics.27.2_31

[8] Bandibas, J. and Takarada, S. (2019) Geoinformation Sharing System for East and Southeast Asia Using SDI, OGC Web Services and FOSS. International Journal of Geosciences, 10, 209-224. https://doi.org/10.4236/ijg.2019.102013

[9] Miao, F. and Yuan, Q. (2013) A WebGIS-Based Information System for Monitoring and Warning of Geological Disasters for Lanzhou City, China. Advances in Meteorology, 2013, Article ID: 769270. https://doi.org/10.1155/2013/769270

[10] Tobita, J., Fukuwa, N. and Mori, M. (2009) Integrated Disaster Simulator Using WebGIS and Its Application to Community Disaster Mitigation Activities. Journal of Natural Disaster Science, 30, 71-82. https://doi.org/10.2328/jnds.30.71

[11] Cozannet, G.L., Bagani, M., Thierry, P., Aragno, C. and Kouokam, E. (2014) WebGIS as Boundary Tools between Scientific Geoinformation and Disaster Risk Reduction Action in Volcanic Areas. Natural Hazards and Earth System Sciences, 14, 1591-1598. https://doi.org/10.5194/nhess-14-1591-2014

[12] Aye, Z.C., Jaboyedoff, M., Derron, M.H., van Westen, C.J., Hussin, H.Y., Ciurean, R.L., Frigerio, S. and Pasuto, A. (2016) An Interactive Web-GIS Tool for Risk Analysis: A Case Study in the Fella River Basin, Italy. Natural Hazards and Earth System Sciences, 16, 85-101. https://doi.org/10.5194/nhess-16-85-2016

[13] Hou, S., Li, A., Han, B. and Zhou, P. (2013) An Early Warning System for Regional Rain-Induced Landslide Hazard. International Journal of Geosciences, 4, 584-587. https://doi.org/10.4236/ijg.2013.43053

[14] Stefanakis, E. and Prastacos, P. (2008) Development of an Open Source-Based Spatial Data Infrastructure. Applied GIS, 4, 1-26.

[15] USGS. https://earthquake.usgs.gov/earthquakes/feed/v1.0/geojson.php

[16] PostgreSQL. http://www.postgresql.org/about/

[17] OGC $_{\mathrm{a}} \cdot$ http://www.opengeospatial.org/standards

[18] MapServer. http://mapserver.org/ogc/wms_server.html

[19] OGC $_{\mathrm{b}}$. http://www.opengeospatial.org/standards/wms

[20] OGC $_{c} \cdot$ http://www.opengeospatial.org/standards/wps

[21] Leaflet. https://leafletjs.com 